\title{
Forest conversion can help to mitigate impacts of climate change on common forest birds
}

\author{
Thomas K. Gottschalk • Tobias E. Reiners
}

Received: 2 August 2014 / Accepted: 26 December 2014 / Published online: 16 January 2015

(C) INRA and Springer-Verlag France 2015

\begin{abstract}
- Key message We forecasted the effects of climate change and forest conversion options on common forest bird species by employing nation-wide high-resolution models. The results give details on how, where, and for which species forest conversion can mitigate climate change effects. - Context To mitigate effects of climate change on forests, alterations are required to convert forests into less vulnerable forest types. Coniferous forest that has been cultivated extensively outside its natural range has been identified as being more vulnerable to climate change effects than deciduous forest.

- Aims The aim is to evaluate the effect of climate change mitigation measures on biodiversity due to forest conversion. - Methods We generated five forest scenarios for Germany in which we systematically replaced coniferous with deciduous forest types. We forecasted the effects of climate change and forest conversion options on 25 forest bird species by employing high-resolution models to predict their current and future ranges and population size.
\end{abstract}

\section{Handling Editor: Thomas WOHLGEMUTH}

Contribution of the co-authors Tobias E. Reiners: running the data analysis and statistical and analytical advice

Electronic supplementary material The online version of this article (doi:10.1007/s13595-014-0455-4) contains supplementary material, which is available to authorized users.

T. K. Gottschalk $(\square)$

University of Applied Forest Sciences,

Schadenweilerhof, 72108 Rottenburg, Germany

e-mail: gottschalk@hs-rottenburg.de

\section{T. E. Reiners}

Conservation Genetics Group, Senckenberg Research Institute and

Natural History Museum Frankfurt, Clamecystrasse 12,

63571 Gelnhausen, Germany

e-mail: tobias.reiners@senckenberg.de
- Results Our simulations and modeling approach clearly predicted that climate change has a stronger impact on populations compared to distribution areas of common forest bird species. Forest conversion was predicted to amplify (15 species) and to weaken (10 species) the predicted gains and losses of species' population size due to climate change. Using the total bird population size to evaluate the mitigation effect of the different forest scenarios, forest conversion below an elevation of $500 \mathrm{~m}$ a.s.l. was predicted to mitigate climate change effects by 0.3 million breeding pairs $(-10 \%)$. The relatively weak mitigation effect was mainly due to few generalist species that inhabit coniferous forests in large abundances and did not profit from a conversion to deciduous forests.

- Conclusion The results of the study give details on how, where, and for which species forest conversion can mitigate the anticipated effects of climate change.

Keywords Coniferous forest - Bird population size .

High-resolution modeling · Germany

\section{Introduction}

Climate change is expected to affect forests ecosystems in various ways. For example, the frequency and severity of forest disturbances, forest growth and productivity, the development of dead wood volume as well as forest succession stages may be modified by climate change (Millar et al. 2007). To mitigate climate change effects on forests, alterations are required to make forests less vulnerable to droughts, heat, and storms (Bolte and Degen 2010). This is necessary because many tree species have been cultivated extensively outside their natural ranges (Spiecker 2003). In Germany, Norway spruce Picea abies is the dominant tree species with $28 \%$ cover (BMELV—Bundesministerium für Ernährung 
2005) and was identified as one of the most vulnerable tree species to climate change effects (Bolte et al. 2009). Deciduous and mixed stands have been recognized as much more tolerant to climate change (Bolte et al. 2009). Without forest management, broad-leaved species would prevail in the majority of German forests and only $0.3 \%$ of all forest areas in Germany would be covered by coniferous forests (Bohn 2011). However, coniferous trees account for $49 \%$ of German forests today (DFWR 2014). In order to increase both resistance and resilience of forests (Schmidt et al. 2010), transformation of coniferous forests to deciduous and mixed forest types is taking place throughout Europe. How these forest management measures will affect biodiversity is largely unknown. Generally, the reliable prediction of ecological and biogeographic responses to climate change and future climate-driven land-use changes poses a serious challenge for ecologists (Jackson et al. 2009). Intensive research has been conducted on projecting climate-driven changes of species distributions, but few studies have attempted to include both climate and land-use variables for predicting species distribution change (Jetz et al. 2007; Braunisch et al. 2014). Typically, spatial studies on the impact of climate change have focused on the prediction of range contractions and range shifts but not on the changes of population size. This is surprising, because many bird species may exhibit population change due to the impact of climate on survival rate and breeding success, independent of a possible change of their geographic distribution (Crick 2004). Following this argument, climate change might have a more immediate influence on a bird species' abundance than on its incidence. Unfortunately, abundance data have often been unavailable on a national scale, and this may have prevented a forecast of population change. Recently, large-scale bird surveys have been implemented, which provide sufficient data necessary to model species distributions and abundances on a national scale (Brotons et al. 2007). The German Common Breeding Bird Survey (GCBBC) is one of the largest monitoring programs for birds. We used this data to estimate the present abundance (20052009) and to predict future changes of the distribution and the population size of 25 forest bird species in Germany, comparing the present climatic conditions with the Intergovernmental Panel on Climate Change (IPCC) emission scenarios A1b and A2 for the period 2021-2050. To forecast the contribution of forest conversion towards mitigating climate change impacts, we used the current distribution of forest types in Germany together with five forest conversion scenarios. In these scenarios, the lower elevation limit of coniferous forest stands was sequentially raised and coniferous forest was sequentially replaced by deciduous and mixed forest types. The distribution of deciduous and mixed forest was based on their natural habitat according to a reconstruction of the current Potential Natural Vegetation (PNV) of Germany (Bohn 2011). Although natural habitats of tree species might change due to future climate change (Lasch et al. 2002) and also nonnative species such as Douglas fir might be planted increasingly, we considered the PNV as an important criterion to direct future forest conversion options.

The objectives of our study were (1) to predict the impact of climate change on the distribution and population of common forest bird species and (2) to evaluate whether forest management measures, here a stepwise conversion of coniferous forests, could mitigate the impacts of climate change on forest bird species. We predicted both species distribution and population size over a large extent $\left(358,077 \mathrm{~km}^{2}\right)$ and at high spatial resolution $(25 \times 25 \mathrm{~m})$.

\section{Materials and methods}

We used four data sources for building the models: (1) bird data from the GCBBS, (2) a high-resolution land-use map, (3) the German digital terrain model, and (4) present climate conditions derived from Deutscher Wetterdienst (DWD). To develop climate and land-use scenarios, we used regional climate simulations of two IPCC emission scenarios (IPCC 2007): A1b and A2 and the PNV of Germany, respectively (Fig. 1).

\subsection{Bird data}

Out of 25 common forest bird species used for this analysis from GCBBS, 22 hold 4-20 \% of the European population in Germany (Table 1) and are of European conservation concern (BirdLife International 2004). The GCBBS is the main scheme for monitoring common and widespread breeding bird species in Germany (Sudfeldt et al. 2012) and is organized by the Federation of German avifaunists (Dachverband Deutscher Avifaunisten, DDA). The GCBBS takes place on 1,300 study plots of $1 \mathrm{~km}^{2}$ which were selected according to the Ecological Area Sampling scheme (EAS). EAS follows a stratified random sampling design, with the stratification based on land use and ecological regions, across the entire terrestrial area of Germany (Hoffmann-Kroll et al. 2003). The GCBBS plots were monitored by highly qualified volunteers in the course of four visits per breeding season (10 March-20 June) using line transect counts of around 3-4$\mathrm{km}$ length inside each recording plot. These curved line transects usually cover a large part of the study plot in order to record most of the birds present.

Bird data from 937 of the 1,300 study plots were available for modeling the species' occurrence probability and the species' abundance. Only those bird records showing breeding behavior, such as singing birds or feeding young and which were recorded within a maximum distance of $150 \mathrm{~m}$ from the line transects, were analyzed. The exact locations of these records were digitized. Birds flying over as well as migratory 
Fig. 1 Flow diagram of the modeling approach used (see Section 2). $R S F$ resource selection function

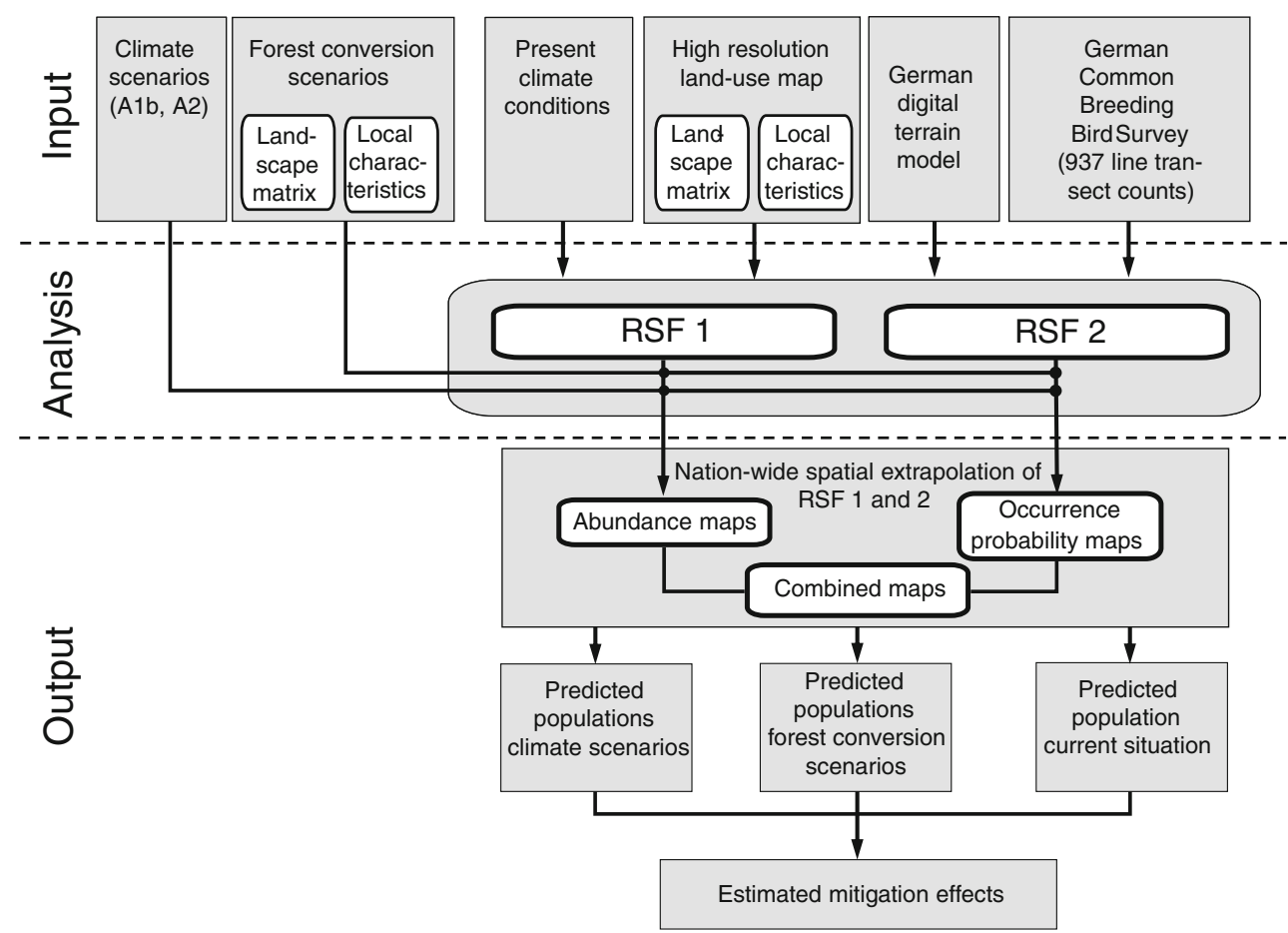

birds, as judged by the expected breeding season of each species, were excluded (Südbeck et al. 2005). For this study we used bird census data collected from study plots between 2005 and 2009. Using data of a 5-year period reduces the bias potentially caused by year-to-year fluctuations in breeding populations of some species, e.g., common chiffchaff, blue tit, and winter wren (Gedeon et al. 2015).

For the presence-absence models, only one observation per species and study plot was selected randomly to avoid autocorrelation and pseudo replication. Thus, a maximum of 937 records per species was used for modeling the species' occurrence probability. One absence point was randomly located in each of those 937 study plots where the species was never recorded as showing breeding behavior. For the abundance models, densities of the 25 bird species within the 937 plots were calculated using distance sampling (Thomas et al. 2010). Therefore, all bird records within the plots were digitized to measure the distance between the bird record and the observer. The distances are needed to calculate the detection probability of each species and between habitat types. With the help of the detection probabilities, abundances were calculated by using the program Distance 6.0 (Thomas et al. 2010), resulting in one estimate per species and plot. The spatial locations of presence-absence and abundance (geographic center of observations) were intersected with all predictor variables.

\subsection{Land-use data and topographic map}

Land-use data were obtained from the Authoritative Topographic Cartographic Information System (ATKIS ${ }^{\circledR}$ ), an object-orientated vector database at the scale of 1:25,000 (http://www.adv-online.de/). Data on forest classes (deciduous forest, mixed forest, coniferous forest, and windthrow areas), orchards, and vineyards were extracted from the Corine Landcover map (DLR 2010). Data on dispersed urban areas were taken from Landsat 7 ETM+ pictures provided by Esch et al. (2009). To account for species-specific habitat relationships, we used a land-use map including 19 land-use classes with emphasis on forest classes and different urban areas. The map was converted from vector format into $25-\mathrm{m}$ resolution raster maps. Additionally, we employed information on single trees, avenue trees, and hedges from ATKIS. This information together with the forest classes was used to calculate distances of each map pixel to (1) forests and (2) single trees, avenues, and hedges.

Topographical data were derived from a German digital terrain model of $25-\mathrm{m}$ resolution provided by Vermessungsverwaltungen der Bundesländer and BKG (2009).

\subsection{Climate data}

Climate variables included temperature and precipitation. For both values, (a) the annual mean and (b) the average of April, May, and June, which corresponds to the birds' main breeding time, were extracted (Table 2). Current climate data for the period 1971-2000 were provided by the DWD (Deutscher Wetterdienst 2010). For future climate projections, we used the A1b and A2 scenarios of the Intergovernmental Panel on 


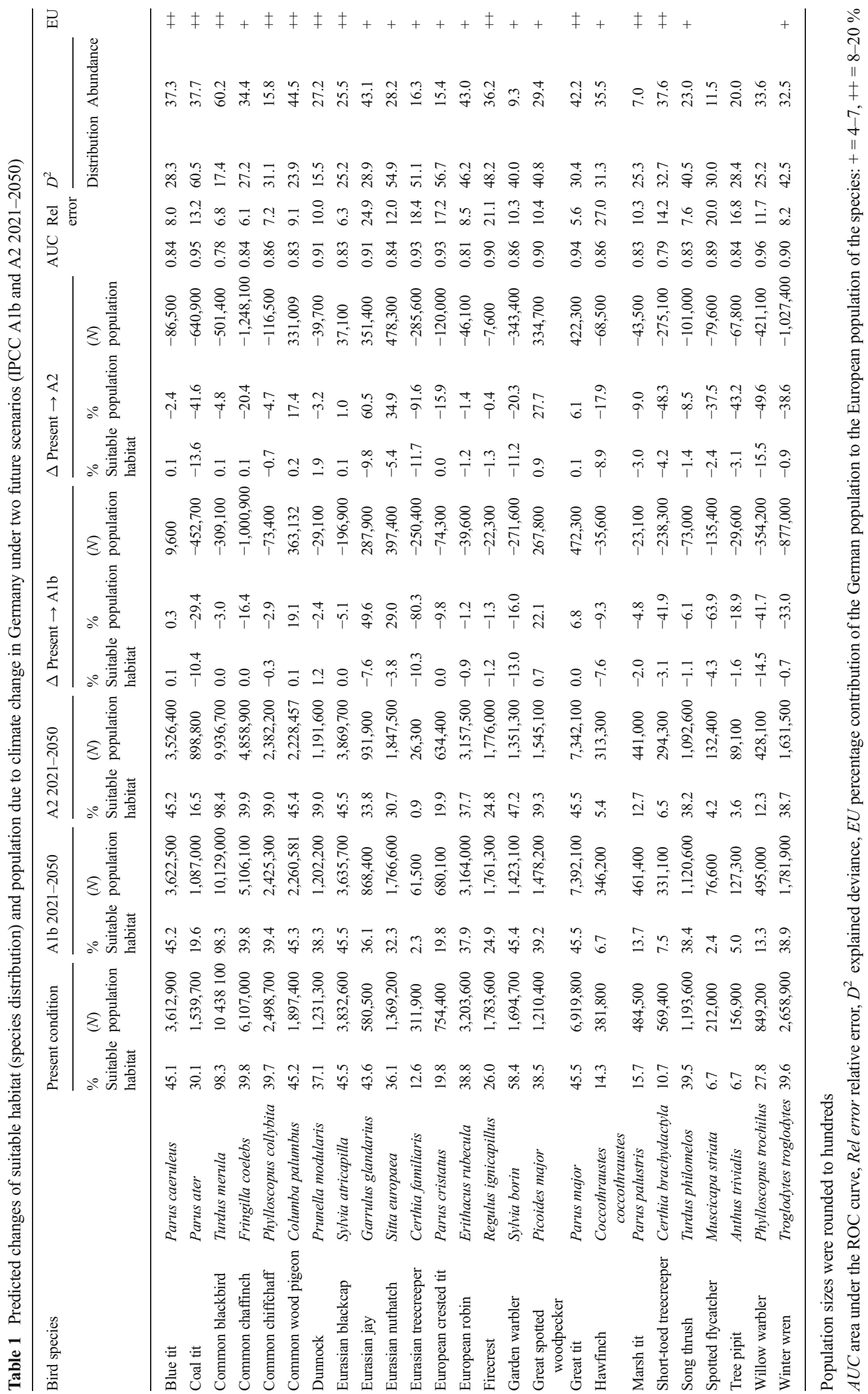


Table 2 Climate variables used in this study and average climate situation in Germany under present and under future conditions (IPCC scenarios A1b and A2, 2021-2050)

\begin{tabular}{llllll}
\hline Climate variable & Present $1971-2000$ & Scenario A1b 2021-2050 & Scenario A2 2021-2050 & $\Delta$ Present ->A1b & $\Delta$ Present ->A2 \\
\hline Annual mean temperature $\left({ }^{\circ} \mathrm{C}\right)$ & 8.6 & 10.1 & 10.4 & +1.5 & +1.8 \\
Spring temperature $\left({ }^{\circ} \mathrm{C}\right)$ & 11.8 & 13.8 & 13.2 & +2.0 & +1.4 \\
Annual precipitation $(\mathrm{mm})$ & 788 & 738 & 708 & -50 & -80 \\
Spring precipitation $(\mathrm{mm})$ & 202 & 176 & 202 & -26 & 0 \\
\hline
\end{tabular}

Climate Change (IPCC 2007). These projections are based on the SRES A1b and A2 emission scenarios (Nakicenovic and Swart 2000) and are projected for the period 2021-2050. In both emission scenarios, a more economic rather than an environmentally sustainable development of the world is assumed. The projected global average surface warming is higher in scenario A2 compared to A1b, as the latter assumes significant innovations in energy technologies. Future climate projections on the scenario A1b were taken from the Statistical Regional model (STAR) (Orlowsky et al. 2008). STAR was developed to generate regional climate projections for the near future and is constrained by a prescribed linear temperature trend which makes it independent of the complex output of general circulation models (GCMs). Simulations made for the SRES A2 emissions scenario were based on three GCMs: CCCMA, HADCM3, and CSIRO (Hijmans et al. 2005). The scenario values were calculated and used to simulate the future distribution and abundance of forest bird species. All climate data were processed in 1-km resolution maps. Second-order polynomials were applied for temperature and precipitation to account for possible nonlinear relationships between predictor variables and dependent variable.

\subsection{Species-habitat models}

Species-habitat relationships were established using both local characteristics of bird locations and characteristics of the landscape matrix surrounding each bird location (Hunter and Gutiérrez 1995; Söderström and Pärt 2000). Local variables included (1) geographic coordinates to account for spatial trends, (2) elevation above sea level derived from the digital elevation model, (3) climate data taken from the present climate map, and (4) the local land use taken from the land-use map; landscape matrix variables encompassed (5) land-use diversity (Shannon index) and (6) percentage cover of specific land-use classes (see Supplementary Table S1 for details). Landscape matrix variables were estimated within a radius of $1,000 \mathrm{~m}$ and were calculated using the SLICER software (Gottschalk et al. 2008). To avoid multi-collinearity, only variables with correlation lower than 0.7 were considered (Fielding and Haworth 1995). From groups of correlated variables, only the variable with the most straightforward ecological interpretation was included. Bibliographical references of each forest bird species were used for preselection of variables (Glutz von Blotzheim and Bauer 1998). For example, the percentage cover of forest edges was only used for those species known to be associated with forest edges, such as tree pipit, garden warbler, and eurasian blackcap (see Supplementary Table S1 for details).

Resource selection functions (RSF) were obtained using generalized linear models (GLM) with binomial error distribution and logit link function (logistic regression) for presence-absence data (RSF 1), and with quasi-Poisson error distribution and logarithmic link function for abundance data (RSF 2). With the help of these functions, two maps, a species occurrence probability map and a species abundance map, were generated. Both maps were coupled in such a way that the map pixels of the abundance map were ignored when the occurrence probability was lower than or equal to 1 minus the actual prevalence of the species (i.e., frequency of study plots that contain the species), as the presence of the species is very unlikely in these areas. While these areas were set to zero, all other values of the presence-absence map were replaced by the predicted values of the abundance map. This two-stage process is known as a hurdle approach (Lack 1954), in which a first model is used to distinguish between zero and positive counts and a second model is used to predict the magnitude of the positive values. The population size of each species was calculated as the total abundance of all pixels of the map. The models presented here were also used for the German Breeding Bird Atlas (Gedeon et al. 2015). Therefore, they were thoroughly checked for regional plausibility regarding the distribution and population size by at least one expert of each of the 16 states of Germany.

Stepwise selection of variables followed the corrected Akaike Information Criterion (AICc) to ensure that the models were exclusively built on meaningful information. To assess the predictive power of the presence-absence models, we calculated the area under the receiver operating characteristic curve (AUC) based on training and test data. This was done by 100 iterations of selecting $80 \%$ of all sampling points to train the model and $20 \%$ to estimate the performance. We used the same approach to estimate the relative error in abundance. The statistical programming environment $\mathrm{R}$ ( $\mathrm{R}$ Development Core Team 2013) was used for these analyses. AUC values range from 0.5 for models with no predictive 
ability to 1.0 for models giving perfect predictions. According to the classification of Hosmer and Lemeshow (2000), AUC values $>0.9$ describe 'outstanding', $>0.8$ 'excellent', and $>0.7$ 'acceptable' discrimination abilities. The percentage deviance explained by each model $\left(D^{2}\right)$ was used to quantify the overall model fit and was regarded as the explanatory power of the model.

The occurrence probability and abundance of each species were predicted under present conditions and under the future climate scenarios. The future scenarios partly extrapolate into novel climates that are outside the range of the current climate situation in Germany. Therefore, we calculated multivariate environmental similarity surface (MESS) maps (Elith et al. 2010) to quantify potential prediction uncertainties within Germany. Each species map was processed in 25-m resolution and therefore contained 774 million pixels. Data preparation, spatial analysis, and map construction were performed in ArcGIS 10.0 (Environmental Science Research Institute Inc., Redlands, CA, USA).

\subsection{Forest conversion scenarios}

Five scenarios were generated where the amount of coniferous forest was sequentially reduced (Fig. 2). As environmental conditions are better for most coniferous tree species at higher elevations (Bohn 2011), we therefore extended the elevation limit stepwise (0-100, 0-300, 0-500, 0-700, 0-900 m a.s.1.) up to which coniferous forest was replaced by deciduous forest or mixed forest in accordance with the current PNV of Germany (Bohn 2011). Thus, the current distribution of coniferous forests was reduced stepwise until the "natural" conditions of the PNV were reached. We did not project or use information of the future distribution of the PNV (Hickler et al. 2012). Deciduous forests increased from presently 9.5 to $21 \%$ cover, and mixed forests increased from presently 6.3 to $9.4 \%$ cover, at maximum. Coniferous forest decreased from 15.4 to $0.8 \%$ cover at minimum, i.e., when the elevation limit of forest conversion was set to $900 \mathrm{~m}$ a.s.l. The effects of forest conversion on the distribution and population of common forest birds were analyzed by keeping the climate situation constant.

\section{Results}

\subsection{Present and future climate}

Up to 2050, the annual mean temperature in Germany was predicted to increase by $1.5{ }^{\circ} \mathrm{C}$ in climate scenario $\mathrm{A} 1 \mathrm{~b}$ and by $1.8{ }^{\circ} \mathrm{C}$ in scenario A2 (Table 2). In contrast, the spring mean temperature was predicted to rise more in scenario A $1 \mathrm{~b}\left(+2.0{ }^{\circ} \mathrm{C}\right)$ than in scenario $\mathrm{A} 2\left(+1.4{ }^{\circ} \mathrm{C}\right)$. Precipitation forecasts predicted a drier climate until 2050 ( -50 and $-80 \mathrm{~mm}$ p.a., respectively). However, less change was predicted for spring precipitation until 2050 (A1b, -26, A2, $\pm 0 \mathrm{~mm}$ ). Of the total area of Germany, 7.3 and $13.4 \%$ were predicted to exceed the current mean of the spring and annual climate conditions, respectively (Fig. 3).

\subsection{Model performance}

Generally, the models showed excellent performance with an average AUC of 0.87 , indicating that the models discriminated predominantly correctly between presence and absence of the birds (Table 1). On average across all species, presence/ absence models explained $35 \%$ of the deviance. However, variation among species was high, ranging from $D^{2}=16 \%$ in the dunnock model to $D^{2}=61 \%$ in the coal tit model (Table 1). The performance of the abundance models was
Fig. 2 Percentage cover of coniferous, mixed, and deciduous forests at present and in five scenarios of forest conversion

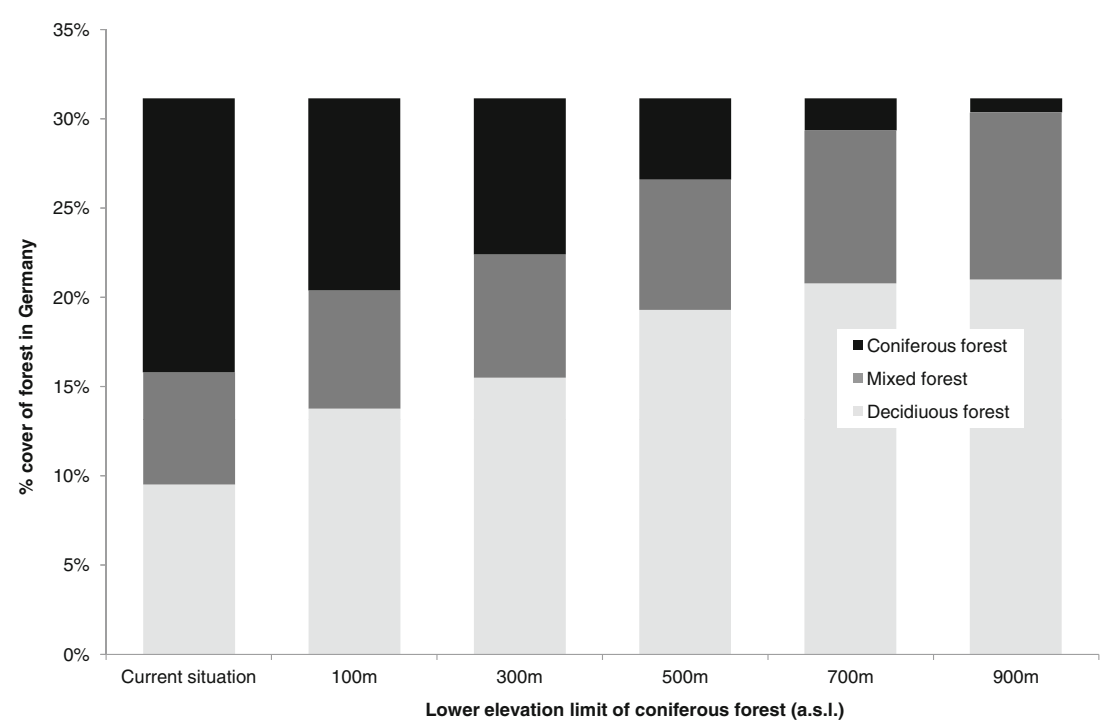


Fig. 3 Potential prediction uncertainties derived from MESS maps. At least one variable (precipitation or temperature of scenario A1b or A2) has a value beyond the current spring (a) or annual (b) climate in Germany. The darker the color, the farther the predicted climate reaches out of the present climate range
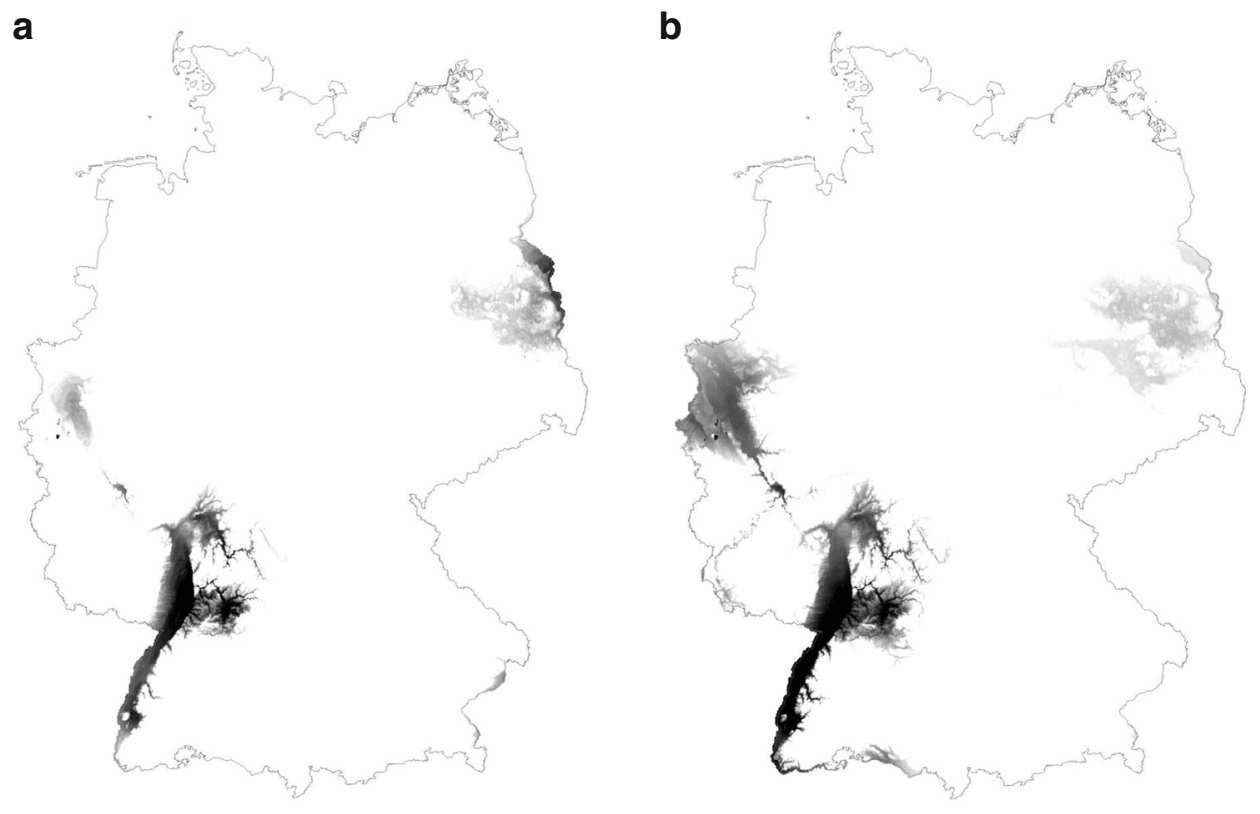

lower, explaining $30 \%$ of the deviance on average. The lowest model performance was attained for the marsh tit $\left(D^{2}=7 \%\right)$ and the best for the common blackbird $\left(D^{2}=60 \%\right)$. The relative error of the abundance model varied between 5.6 and $27.0 \%$ (mean value $12.4 \%$ ).

On average, $D^{2}$ significantly decreased by about $17.0 \%$ when the climate variables were omitted from the models and by about $33.2 \%$ when the land-use variables were omitted from the models (Wilcoxon signed rank test, $P<0.001)$. Similarly, the AUC value significantly decreased, on average, about 0.22 when the land-use variables were omitted from the models and 0.09 when the climate variables were omitted from the models (Wilcoxon signed rank test, $P<0.001$ ).

All bird species responded at least to one of the climate variables. However, in a few single models, the climate variables were not selected by the AICc (occurrence probability model of eurasian crested tit, abundance model of European robin, Eurasian treecreeper, and spotted flycatcher), but this was never the case in both models (Table S1).

\subsection{Predicted changes of bird distributions due to climate change}

The area within Germany that was modeled as suitable habitat under present climate conditions varied widely between the 25 bird species and ranged from $6.7 \%$ for the spotted flycatcher to $98.3 \%$ for the common blackbird (Table 1, Fig. S1). The distribution range was predicted to decrease for 19 and 21 bird species (scenarios A1b and A2) and to increase for six and four bird species (scenarios A1b and A2) within Germany, owing to future climate change (Table 1, Fig. 4a). Strong losses of more than $10 \%$ decrease of distribution range were predicted for the coal tit (scenarios A1b and A2), eurasian treecreeper (scenarios A1b and A2, Fig. 5), garden warbler (scenarios A1b and A2), and willow warbler (scenarios A1b and A2). No species was predicted to gain suitable habitat of more than $10 \%$ in future climate scenarios.

3.4 Predicted changes of breeding populations due to climate change

On average, the percentage change in breeding population size $(-10.4$ and $-12.5 \%)$ was higher than the percentage change of distribution range $(-3.2$ and $-3.6 \%)$ in climate scenarios $\mathrm{A} 1 \mathrm{~b}$ and A2, respectively. More than $10 \%$ change in population size was predicted for 13 (scenario A1b) and 15 species (scenario A2) (Fig. 4b, Fig. S1). The eurasian treecreeper (scenarios A1b and A2) and spotted flycatcher (scenario A1b) were predicted to lose more than $50 \%$ of their breeding population. Four species were predicted to increase their population by more than $10 \%$ under scenarios A1b and A2. More than $50 \%$ population increase was predicted for the eurasian jay ( $+60 \%$ in scenario A2). While six species were predicted to increase their population, 19 were predicted to decrease their population in both scenarios $\mathrm{A} 1 \mathrm{~b}$ and A2. In total, a loss of 2.7 and 3.6 million breeding pairs $(-10.4$ and $-12.5 \%)$ was predicted for scenarios A1b and A2 in Germany, respectively (Fig. 6). Two species were predicted to lose more than 1 million breeding pairs (Table 1, Fig. 6): common chaffinch $(-1.0$ million in scenario A1b, -1.2 million in scenario A2) and winter wren $(-0.9$ million in scenario $\mathrm{A} 1 \mathrm{~b},-1.0$ million in scenario A2). The three largest population gains were predicted for eurasian nuthatch $(+0.4$ million in scenario A1b,+0.5 
Fig. 4 Percentage change of suitable habitat (a) and percentage change of population size (b) of 25 common forest bird species in Germany due to climate change (IPCC scenario A1b and A2, 2021-2050). Bird species are sorted by change of suitable habitat in scenario $\mathrm{A} 2$

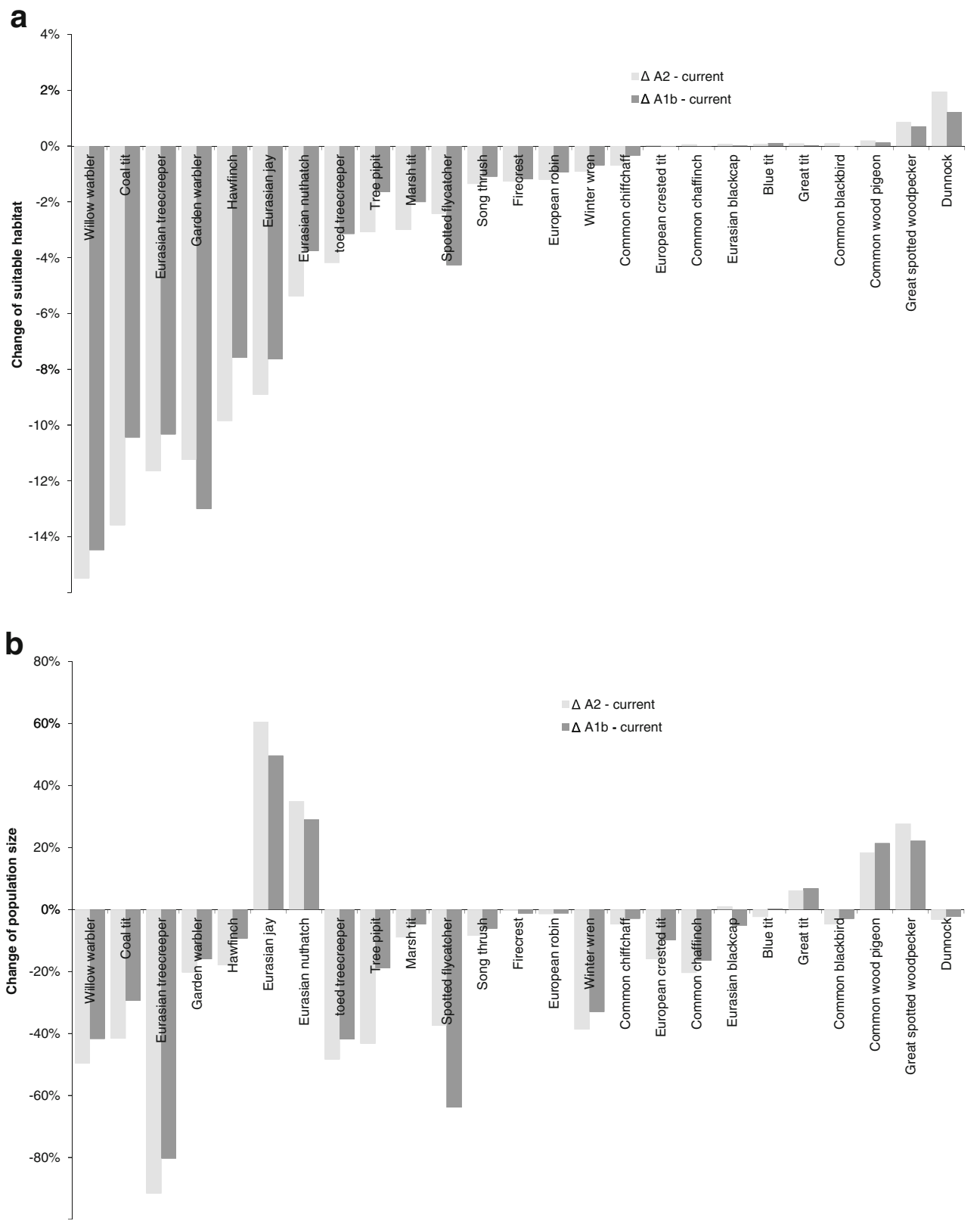

million in scenario A2) and great tit ( +0.5 million in scenario A1b, +0.4 million in scenario A2).

Three species showed a contrasting response to climate change of their distribution range and their population size. This was most obvious in the eurasian jay $(9.8 \%$ loss of distribution range but $60.5 \%$ increase in population size in scenario A2) and eurasian nuthatch $(5.4 \%$ loss of distribution range but $34.9 \%$ increase in population size in scenario A2).

\subsection{Predicted changes due to forest conversion}

The population size of 14 out of the 25 bird species was predicted to increase following the conversion of forests in
Germany (Table 3, Fig. 6). Below an elevation of $500 \mathrm{~m}$ a.s.l., the conversion of coniferous forest into deciduous and mixed forest led to an increase of the total forest bird population ranging between a gain of 0.2 million breeding pairs (300 m elevation) and 0.32 million breeding pairs (100 m elevation). In contrast, the total population was predicted to decrease by 0.50 million breeding pairs if the coniferous forests were converted below an elevation of $900 \mathrm{~m}$ a.s.l. In this scenario, the highest reduction was predicted for chaffinch ( -0.96 million), European crested tit $(-0.64$ million) and coal tit ( -0.59 million breeding pairs) and the highest increase for great tit $(+0.44$ million), blue tit $(+0.43$ million), hawfinch $(+0.35$ million $)$, and marsh tit $(+0.34$ million). 
Fig. 5 Present (a) and future (b) distribution and abundance pattern of the eurasian treecreeper in Germany. This species is predicted to lose large areas of its distribution due to climate change (IPCC scenario A2, 2021-2050). Red color displays high abundance; yellow color displays low abundance. Maps on the prediction of all forest bird species used in this study are provided as supporting information
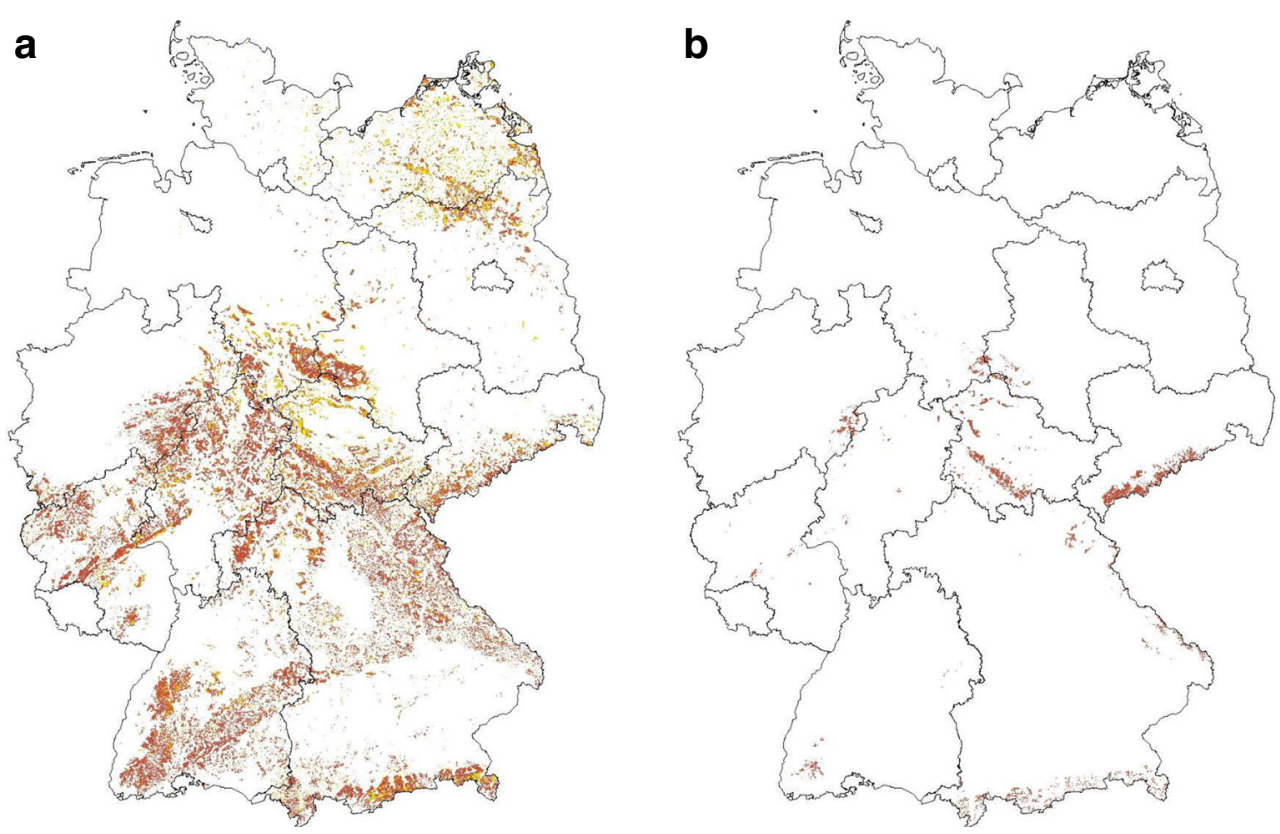

3.6 Predicted changes due to climate change and forest conversion

Forest conversion-modulated climate change effects in such a way that it amplified (15 species) and weakened (10 species) the predicted gains and losses of the species' population size due to climate change (Fig. 6). Based on our results, forest conversion mitigated the climate-driven effect of 19 bird species losing and six bird species gaining in population size to 14 bird species losing and 11 bird species gaining in population size (scenarios A2). Using the total bird population size to evaluate the mitigation effect of different forest scenarios, the forest conversion below an elevation of $500 \mathrm{~m}$ a.s.l. mitigated climate-driven losses. The decrease of the total population size could be mitigated by $10 \%$ from -2.2 to -1.9 million breeding pairs and from -3.5 to -3.2 million breeding pairs in scenarios A1b and A2, respectively. The strongest mitigation effects were predicted for marsh tit, hawfinch, blue tit, and European robin, with forest conversion completely compensating for climate-driven population losses in these species. Nevertheless, the total population was predicted to decrease if forest conversion were to be realized above $500 \mathrm{~m}$ a.s.l.
Fig. 6 Change of population size of 25 common forest bird species in Germany due to climate change (IPCC scenario A2, 2021-2050) only and due to climate change and conversion of coniferous forest to deciduous and mixed forest

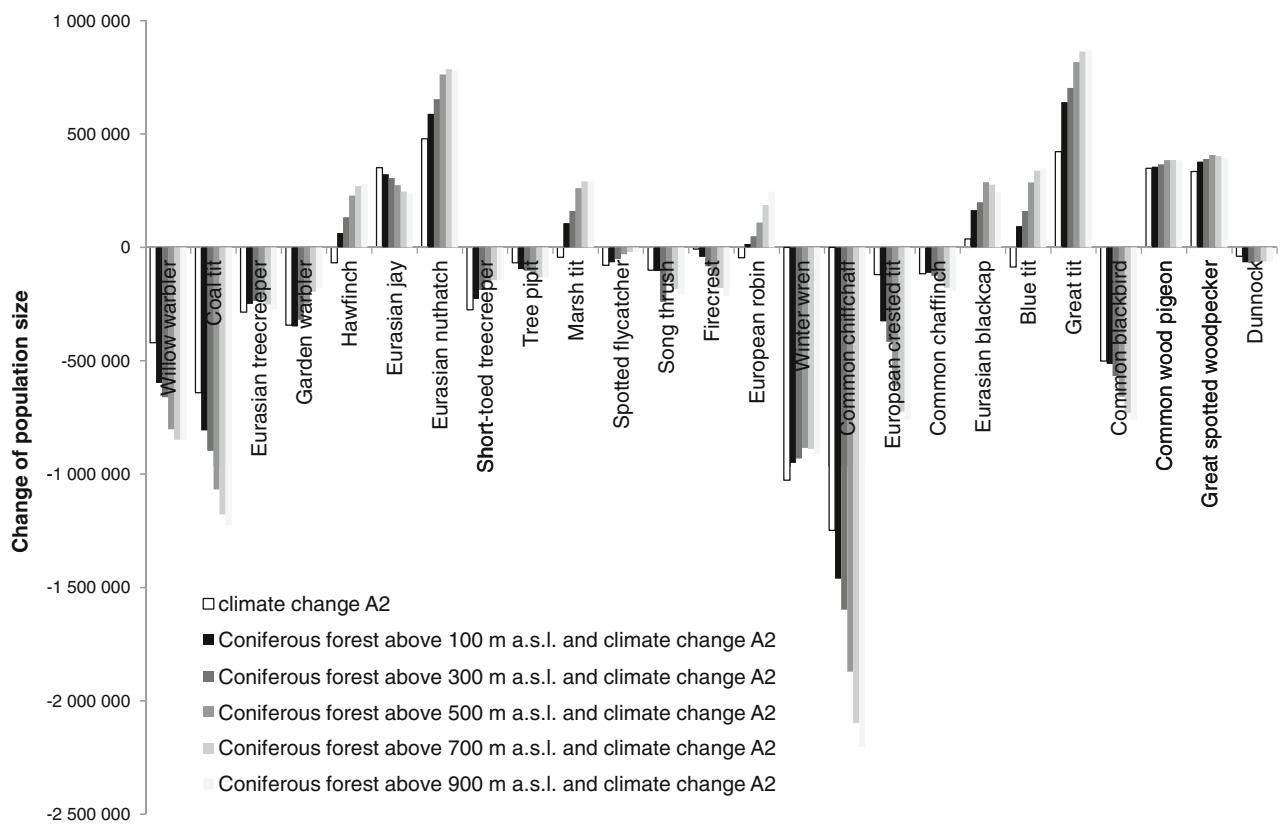


Table 3 Predicted changes in population size of 25 common forest bird species in Germany due to transformation of coniferous forests to deciduous and mixed forest types and taking current climate conditions into account

Transformation was conducted step-by-step by increasing the lower elevation limit of coniferous forests stands. Population sizes were rounded to hundreds

\begin{tabular}{|c|c|c|c|c|c|}
\hline \multirow[t]{2}{*}{ Bird species } & \multicolumn{5}{|c|}{ Lower elevation limit of coniferous forest (a.s.1.) } \\
\hline & $100 \mathrm{~m}$ & $300 \mathrm{~m}$ & $500 \mathrm{~m}$ & $700 \mathrm{~m}$ & $900 \mathrm{~m}$ \\
\hline Common chaffinch & $-212,900$ & $-349,500$ & $-623,800$ & $-849,600$ & $-955,000$ \\
\hline European crested tit & $-206,200$ & $-296,400$ & $-490,200$ & $-604,100$ & $-638,500$ \\
\hline Willow warbler & $-176,500$ & $-239,100$ & $-380,400$ & $-426,100$ & $-426,800$ \\
\hline Coal tit & $-165,300$ & $-255,900$ & $-427,500$ & $-536,500$ & $-585,000$ \\
\hline Firecrest & $-33,400$ & $-75,400$ & $-118,700$ & $-171,200$ & $-206,000$ \\
\hline Eurasian jay & $-29,500$ & $-45,600$ & $-78,100$ & $-106,300$ & $-116,300$ \\
\hline Tree pipit & $-27,500$ & $-34,900$ & $-53,100$ & $-62,600$ & $-64,000$ \\
\hline Dunnock & $-26,100$ & $-29,000$ & $-22,700$ & $-22,100$ & $-24,400$ \\
\hline Common blackbird & $-12,100$ & $-65,600$ & $-156,900$ & $-228,200$ & $-257,500$ \\
\hline Garden warbler & $-4,700$ & 24,800 & 96,200 & 149,200 & 164,700 \\
\hline Song thrush & $-3,000$ & $-138,400$ & $-41,300$ & $-81,200$ & $-104,900$ \\
\hline Common chiffchaff & 4,900 & $-8,300$ & $-32,800$ & $-60,600$ & $-75,900$ \\
\hline Spotted flycatcher & 14,200 & 28,600 & 49,800 & 58,900 & 60,600 \\
\hline Common wood pigeon & 23,600 & 33,800 & 53,000 & 54,100 & 50,800 \\
\hline Eurasian treecreeper & 36,600 & 49,200 & 60,100 & 34,000 & 14,100 \\
\hline Great spotted woodpecker & 42,300 & 54,700 & 72,100 & 67,100 & 60,600 \\
\hline Short-toed treecreeper & 48,000 & 87,500 & 121,900 & 131,200 & 131,900 \\
\hline European robin & 61,000 & 94,600 & 154,300 & 232,300 & 291,400 \\
\hline Winter wren & 77,200 & 97,300 & 143,400 & 138,600 & 120,000 \\
\hline Eurasian nuthatch & 110,100 & 174,400 & 283,400 & 306,100 & 298,400 \\
\hline Eurasian blackcap & 126,100 & 161,100 & 249,000 & 238,500 & 206,200 \\
\hline Hawfinch & 131,900 & 200,100 & 295,900 & 338,300 & 345,500 \\
\hline Marsh tit & 149,600 & 203,000 & 303,800 & 333,900 & 335,000 \\
\hline Blue tit & 179,100 & 246,000 & 371,500 & 423,900 & 433,800 \\
\hline Great tit & 217,100 & 280,900 & 394,200 & 440,100 & 444,200 \\
\hline Total & 324,500 & 197,900 & 223,100 & $-202,300$ & $-497,100$ \\
\hline
\end{tabular}

\section{Discussion}

The objective of this study was to predict the responses of common forest bird species to expected climate change and to forest conversion across the area of Germany. Due to the use of a detailed spatial land use and climate data model, the performance indicated by AUC was relatively high as were the model fits indicated by $D^{2}$. Although the estimated error in abundance revealed a certain level of uncertainty and the fact that predictions of species distributions and abundances under climate change are subject to different sources of uncertainty (e.g., Barbet-Massin et al. 2010; Synes and Osborne 2011; Braunisch et al. 2013), we strongly believe that our model results at least allow relative comparisons between the current situation and the scenarios. Our predictions of population sizes were used to comparatively evaluate different scenarios with the current reference condition. Therefore, one single value of a predicted species population might not be used as an absolute estimate of a future condition.

\subsection{Predicted changes of species distribution}

The models projected very different spatial distribution patterns of the bird species in the climate scenarios. Nevertheless, consistent effects regarding all common forest bird species were predicted for Germany during the coming decades, with concomitant consequences for the German forest avifauna. More bird species were predicted to lose than to gain suitable habitat following climate change. For example, the drastic narrowing of the distribution range with loss of more than $10 \%$ area in Germany was predicted for the eurasian treecreeper and willow warbler. This is broadly in line with the prediction for these species by Huntley et al. (2007), although they forecasted a decline by more than $60 \%$ up to 2100. The differences can be attributed to the dissimilar methods used in the two studies. Huntley et al. (2007) used a different climate scenario (SRES scenario B2), projected to a different time period (2070-2099) and worked on a different spatial scale (50-km resolution). Nationwide studies forecasting 
the distribution or population size of common bird species in Europe are scarce and therefore we cannot compare our data with many others. A study focusing on 27 northern land birds of Finland (Virkkala et al. 2008) predicted much stronger changes of distribution ranges. The authors forecasted an average area loss of $58 \%$ for the period 2021-2050 (scenario A2). This can be attributed to the stronger temperature increase and faster climate change expected in the northern latitudes (Loarie et al. 2009).

\subsection{Predicted population changes}

Our models clearly predicted that climate change will have a relatively stronger impact on populations than on distribution areas of forest birds. This may reflect the fact that we used ubiquitous species with a wide distribution in Germany for modeling. The distribution patterns of these species may be less sensitive to moderate climate effects. In the climate scenarios, different and even opposing trends of distribution area and population size were predicted for four bird species, suggesting that the change of habitat and change of abundance are influenced by different mechanisms. For example, the eurasian jay was predicted to lose suitable habitat in urban areas as well as in forests at lower elevations, but to resist climate change in forests at higher elevations, where the species was predicted to increase in abundance. Thus, in spite of a net habitat loss, the population is expected to profit from climate change. Previous studies have documented the fact that species do not always exhibit positive abundance-occupancy (Chamberlain and Fuller 2001), which is congruent with our model predictions.

We modeled breeding birds because the breeding period is crucial within a bird's life cycle. Our investigation clearly focuses on climate effects in the breeding habitat. However, climate change can affect survival during all seasons and can cause temporal bottlenecks outside the reproduction period, for example, if suitable habitat is reduced in the wintering grounds (Saether 2000). Unfortunately, winter records of birds in Europe and in Africa are not systematically collected and are not available in the quality required to reach high modeling performance (Gottschalk et al. 2011). We do not envisage that modeling climate effects on winter habitats of birds will be possible in the near future. On a coarse resolution, Doswald et al. (2009) explored the potential impacts of climatic change on breeding and wintering ranges of Sylvia warblers. They showed that migratory species can be expected to suffer greater negative impacts from climate change than resident species because migration distances can substantially increase owing to climate change.

We identified those areas where predicted future climate conditions exceeded the present range of conditions in Germany. Projections of bird distributions within these areas bear a higher uncertainty. Barbet-Massin et al. (2010) suggested that data from the entire distribution range is required to correctly capture the full climatic potential of a species. Thus, to overcome this type of uncertainty, we see two main challenges which will control progress in the future: (1) the establishment of spatially extensive and accurate bird records and (2) the use of spatially extensive high-resolution land-use data covering the whole distribution area of a species.

\section{Scenarios on forest conversion}

In order to limit the model complexity, we decided not to include socioeconomic drivers and some of the environmental drivers such as soil conditions, surface inclination, and microclimate. We did not address interactions between climate change and land use, which may have important consequences (Oliver and Morecroft 2014), e.g., more frequent or more intense disturbance, such as drought and windthrow, which can result in an increase of mass insect outbreaks and therefore a change in food availability. Climate change can also directly influence plant species composition and even the climax vegetation type expected in any given region, which can affect habitat quality, food resources, interspecific competition, or predator populations (Ockendon et al. 2014). Furthermore, we did not consider non-native tree species, especially Douglas fir Pseudotsuga menziesii which in some regions has become an attractive alternative as a commercial tree species (Beinhofer and Knoke 2010) and is predicted to be increasingly cultivated in future Central European forests (Curt et al. 2001). Specieshabitat relationships of European bird species on Douglas fir have not been studied extensively, but the study of Goßner and Utschick (2002) suggests a lower food availability in winter and the study of Müller and Stollenmaier (1994) a lower breeding bird density. All these changes can affect bird abundances and bird community composition. Climate change affects not only composition and configuration of forests (Bolte and Degen 2010) but also forest structure and the relative performance of tree species (Hanewinkel et al. 2013), which may on the one hand amplify negative climate-related impacts on species' habitats but also offers additional potential for mitigation (Braunisch et al. 2014).

We were not able to consider most of the points mentioned here, as explicit spatial data (e.g., predictions on extreme climate events, maps on Douglas fir distribution, and maps on forest structure) were not available at a highly spatial resolution and on a national scale to be used for our modeling approach. However, we used common generalist bird species, which are not as dependent on specific forest structure as specialists, such as woodpeckers or grouse (Sachot et al. 2003; Müller et al. 2009). It is possible that such specialist birds will respond more strongly to both climate-driven and management-driven changes of forests than is projected by our models of common forest birds. All bird species involved 
in this study are known to occur in both coniferous and deciduous forest and even outside deep forests but show diverse abundances in these habitats (Gottschalk and Huettmann 2011). This point strengthens the need to involve abundance data if the effect of climate change and mitigation measures is to be predicted. However, some of the species only occur in coniferous or deciduous forests if sufficient breeding possibilities are available, e.g., nest boxes for the marsh tit in evenaged coniferous forest and young trees or an extensive shrub layer for dunnock and garden warbler in coniferous forest (Glutz von Blotzheim and Bauer 1998). The diverse abundance of the species resulted in different magnitudes of the mitigation effects.

The performance of the presence-absence bird models decreased more when land-use variables were omitted rather than when climate variables were omitted as predictors. This difference might partly be caused by the different grain sizes of the two sets of data used, as Gottschalk et al. (2011) have shown this phenomenon for land-use data. We found no evidence that abundance or distribution pattern of common birds might be affected by climatic differences smaller than $1 \mathrm{~km}$ in resolution. Although this hypothesis needs further investigation, our results suggest a relatively higher importance of land use in determining common bird species distributions. The results of the study of Eglington and Pearce-Higgins (2012) underpin our findings. They suggest that land-use change has been a more significant driver of bird declines than climate change. Thus, the investigated changes of land use, i.e., conversion of forest types to mitigate climate change effects on birds, seem to be a very promising approach. Our results indicate that 11 out of 25 common forest bird species would profit from a conversion of coniferous forest into deciduous and mixed forest, as this would mitigate negative or positive climate change effects on species' population. This relatively weak mitigation effect of forest conversion can be attributed to a relatively low amount of changed land cover. Less than $15 \%$ of the total German land cover was converted in this study and changes affected forest types in which all bird species occur, although in different densities. In particular, eurasian nuthatch, marsh tit, hawfinch, blue tit, and garden warbler are well known to prefer deciduous and mixed forest stands (Glutz von Blotzheim and Bauer 1998). Furthermore, the relatively weak mitigation effect of forest conversion on total population loss is explained by a number of species which are very abundant in coniferous forests, especially the common chaffinch, European crested tit, and coal tit (Gottschalk and Huettmann 2011). They are predicted to decrease by 4.2 million breeding pairs if coniferous forest is converted below $900 \mathrm{~m}$ a.s.l. The negative response of these birds effectively counteracts a higher increase on the total forest bird population. However, the total population cannot be used as the sole measure to assess forest scenarios, as it depends on the species selected for modeling and the fact that increasing numbers in one species might not compensate for losses in another species. Current bird species composition of German forests does not indicate natural forest stands and might not be considered a target situation in terms of forest ecosystem functions and conservation in central Europe. Independent of the low mitigation effect depicted for the current bird species, the envisaged forest conversion to more natural stands will increase the resilience of forest ecosystems and therefore increase their capacity to absorb external pressures of changing environmental conditions over time.

\section{Conclusions}

In summary, our modeling approach is limited by lack of data on change effects in the wintering grounds, on the implications of introducing new tree species, and on the importance of habitat detail such as forest structure. In recognition of these limitations, our models represent a pragmatic approach based on what we know now, combining some of the best data currently available on a national scale and the highest spatial resolution we were currently able to handle. Probably the most immediate progress in assessing the responses of forest birds to climate change and forest conversion could be obtained by sampling forest structure parameters in the GCBBS plots and by assessing a broad set of forest structure change scenarios in combination with changing climate.

Our models predict that distribution ranges and population sizes of forest birds in Germany will be substantially affected under climate change expected up to 2050 . A conversion of coniferous forests to deciduous and mixed forests can partly though not completely mitigate the anticipated negative effects of climate change on current bird species populations. Due to the use of highresolution models, we can provide detailed spatial results on a regional scale on how and for which species forest conversion can mitigate the anticipated effects of climate change.

Acknowledgments We gratefully thank K. Ekschmitt for his statistical advice throughout the study and in helping to draft the first version of the manuscript. We are deeply grateful to more than 800 amateur ornithologists who conducted the bird census work and to the Dachverband Deutscher Avifaunisten (DDA) for providing the bird census data and for giving helpful advice. We are grateful to all colleagues working in this project, especially to Bianca Müller for her extensive support of the GIS work. We thank Jan Engler helping to provide the MESS maps and two anonymous reviewers and Thomas Wohlgemuth for improving the manuscript.

Funding Parts of the study were supported by the Federal Agency for Nature Conservation (BfN) on behalf of the German Ministry of Environment, Nature Protection and Nuclear Safety (reference number 350882 0300) and by the German Science Foundation (DFG) in the project GO 1096/2-1. 


\section{References}

Barbet-Massin M, Thuiller W, Jiguet F (2010) How much do we overestimate future local extinction rates when restricting the range of occurrence data in climate suitability models? Ecography 33:878886

Beinhofer B, Knoke T (2010) Financially advantageous proportion of Douglas fir in a tree species portfolio. Forstarchiv 81:255-265

BirdLife International (2004) Birds in Europe: population estimates, trends and conservation status, Cambridge

BMELV—Bundesministerium für Ernährung LuV (2005) Die zweite Bundeswaldinventur. Der Inventurbericht, Bonn

Bohn U (2011) Karte der potentiellen natürlichen Vegetation Deutschlands, 1:500.000. Bundesamt für Naturschutz, Bonn

Bolte A, Degen B (2010) Forest adaptation to climate change - options and limitations. Landbauforschung - Appl Agric For Res 60:111-118

Bolte A, Eisenhauer D-R, Ehrhart H-P, Groß J, Hanewinkel M, Kölling C, Profft I, Rohde M, Röhe P, Amereller K (2009) Climate change and forest management - accordances and differences between the German states regarding assessments for needs and strategies towards forest adaptation. Landbauforschung-Appl Agric For Res 59:269-278

Braunisch V, Coppes J, Arlettaz R, Suchant R, Schmid H, Bollmann K (2013) Selecting from correlated climate variables: a major source of uncertainty for predicting species distributions under climate change. Ecography 36:971-983

Braunisch V, Coppes J, Arlettaz R, Suchant R, Zellweger F, Bollmann K (2014) Temperate mountain forest biodiversity under climate change: compensating negative effects by increasing structural complexity. PLoS ONE 9:e97718

Brotons L, Herrando S, Pla M (2007) Updating bird species distribution at large spatial scales: applications of habitat modelling to data from long-term monitoring programs. Divers Distrib 13:276-288

Chamberlain DE, Fuller RJ (2001) Contrasting patterns of change in the distribution and abundance of farmland birds in relation to farming system in lowland Britain. Glob Ecol Biogeogr 10:399-409

Crick HQP (2004) The impact of climate change on birds. Ibis 146:48-56

Curt T, Bouchaud M, Agrech G (2001) Predicting site index of DouglasFir plantations from ecological variables in the Massif Central area of France. For Ecol Manag 149:61-74

Deutscher Wetterdienst (2010) CDC: Das Klimadatenzentrum des Deutschen Wetterdienstes. http://cdc.dwd.de/catalogue/srv/de/ main.home. Accessed 3 Apr 2014

DFWR (2014) Die Baumarten und ihre Aufteilung. http://www. forstwirtschaft-in-deutschlandde/waelder-entdecken/baumarten/. Accessed 3 Apr 2014

DLR (2010) CORINE land cover 2006. Deutsches Zentrum für Luft- und Raumfahrt, Oberpfaffenhofen

Doswald N, Willis SG, Collingham YC, Pain DJ, Green RE, Huntley B (2009) Potential impacts of climatic change on the breeding and non-breeding ranges and migration distance of European Sylvia warblers. J Biogeogr 36:1194-1208

Eglington S, Pearce-Higgins J (2012) Disentangling the relative importance of changes in climate and land-use intensity in driving recent bird population trends. PLoS One 7:e30407

Elith J, Kearney M, Phillips S (2010) The art of modelling range-shifting species. Method Ecol Evol 1:330-342

Esch T, Himmler V, Schorcht G, Thiel M, Wehrmann T, Bachofer F, Conrad C, Schmidt M, Dech S (2009) Large-area assessment of impervious surface based on integrated analysis of single-date Landsat-7 images and geospatial vector data. Remote Sens Environ 113:1678-1690

Fielding AH, Haworth PF (1995) Testing the generality of bird-habitat models. Conserv Biol 9:1466-1481

Gedeon K, Grüneberg C, Mitschke A, Sudfeldt C, Eikhorst W, Fischer S, Flade M, Frick S, Geiersberger I, Koop B, Kramer M, Krüger T,
Roth N, Ryslavy T, Schlotmann F, Stübing S, Sudmann SR, Steffens R, Vökler F, Witt K (2015) Atlas Deutscher Brutvogelarten, Stiftung Vogelmonitoring Deutschland und Dachverband Deutscher Avifaunisten, Hohenstein-Enstthal und Münster

Glutz von Blotzheim UN, Bauer KM (eds) (1998) Handbuch der Vögel Mitteleuropas eBook. AULA GmbH, Wiesbaden

Goßner M, Utschick H (2002) Douglas fir stands deprive wintering bird species of food resource. Neobiota 3:105-121

Gottschalk TK, Aue B, Hotes S, Ekschmitt K (2011) Influence of grain size on species-habitat models. Ecol Model 222:3403-3412

Gottschalk TK, Bertling M, Wolters V, Biermann J (2008) A new MW algorithm to speed up landscape index calculation of high resolution maps. In: Schiewe J, Michel U (eds) Geoinformatics paves the highway to digital Earth. Institut für Geoinformatik und Fernerkundung, University of Osnabrück, Osnabrück, pp 29-32

Gottschalk TK, Huettmann F (2011) Comparison of distance sampling and territory mapping methods for birds in four different habitats. J Ornithol 152:421-429

Hanewinkel M, Cullmann DA, Schelhaas M-J, Nabuurs G-J, Zimmermann NE (2013) Climate change may cause severe loss in the economic value of European forest land. Nat Clim Chang 3:203-207

Hickler T, Vohland K, Feehan J, Miller PA, Smith B, Costa L, Giesecke T, Fronzek S, Carter TR, Cramer W, Kuehn I, Sykes MT (2012) Projecting the future distribution of European potential natural vegetation zones with a generalized, tree species-based dynamic vegetation model. Glob Ecol Biogeogr 21:50-63

Hijmans RJ, Cameron SE, Parra JL, Jones PG, Jarvis A (2005) Very high resolution interpolated climate surfaces for global land areas. Int $\mathrm{J}$ Climatol 25:1965-1978

Hoffmann-Kroll R, Schäfer D, Seibel S (2003) Landscape indicators from ecological area sampling in Germany. Agric Ecosyst Environ 98: 363-370

Hosmer DW, Lemeshow S (2000) Applied logistic regression. Wiley, New York

Hunter JE, Gutiérrez RJ (1995) Habitat configuration around spotted owl sites in northwestern California. Condor 97:684-693

Huntley B, Green RE, Collingham YC, Willis SG (2007) A climatic atlas of European breeding birds. Lynx Edicions, Barcelona

IPCC (2007) Intergovernmental panel on climate change fourth assessment report: climate change 2007. http://www.ipcc.ch/publications and data/publications_and data_reports.html

Jackson ST, Betancourt JL, Booth RK, Gray ST (2009) Ecology and the ratchet of events: climate variability, niche dimensions, and species distributions. PNAS 106:19685-19692

Jetz W, Wilcove DS, Dobson AP (2007) Projected impacts of climate and land-use change on the global diversity of birds. PLoS Biol 5:e157. doi:10.1371/journal.pbio.0050157

Lack D (1954) The natural regulation of animal numbers. Oxford University Press, Oxford

Lasch P, Lindner M, Erhard M, Suckow F, Wenzel A (2002) Regional impact assessment on forest structure and functions under climate change - the Brandenburg case study. For Ecol Manag 162:73-86

Loarie SR, Duffy PB, Hamilton H, Asner GP, Field CB, Ackerly DD (2009) The velocity of climate change. Nature 462:1052-1055

Millar CI, Stephenson NL, Stephens SL (2007) Climate change and forests of the future: managing in the face of uncertainty. Ecol Appl 17: 2145-2151

Müller J, Pollath J, Moshammer R, Schroder B (2009) Predicting the occurrence of middle spotted woodpecker Dendrocopos medius on a regional scale, using forest inventory data. For Ecol Manag 257: 502-509

Müller J, Stollenmaier S (1994) Effects of growing Douglas fir on birdlife. AFZ, Allg Forst Z 49:237-239

Nakicenovic N, Swart R (2000) Emissions scenarios. Special report of the Intergovernmental Panel on Climate Change. Cambridge University Press, Cambridge 
Ockendon N, Baker DJ, Carr JA, White EC, Almond REA, Amano T, Bertram E, Bradbury RB, Bradley C, Butchart SHM, Doswald N, Foden W, Gill DJC, Green RE, Sutherland WJ, Tanner EVJ, PearceHiggins JW (2014) Mechanisms underpinning climatic impacts on natural populations: altered species interactions are more important than direct effects. Glob Chang Biol 20:2221-2229

Oliver TH, Morecroft MD (2014) Interactions between climate change and land use change on biodiversity: attribution problems, risks, and opportunities. WIREs Clim Chang 5:317-335

Orlowsky B, Gerstengarbe F-W, Werner PC (2008) A resampling scheme for regional climate simulations and its performance compared to a dynamical RCM. Theor Appl Climatol 92:209-223

R Development Core Team (2013) R: a language and environment for statistical computing. R Foundation for Statistical Computing, Vienna, http://www.R-project.org/

Sachot S, Perrin N, Neet C (2003) Winter habitat selection by two sympatric forest grouse in western Switzerland: implications for conservation. Biol Conserv 112:373-382

Saether B-E (2000) Weather ruins winter vacations. Science 288:1975-1976

Schmidt M, Hanewinkel M, Kändler G, Kublin E, Kohnle U (2010) An inventory-based approach for modeling single tree storm damageexperiences with the winter storm 1999 in southwestern Germany. Can J For Res 40:1636-1652
Söderström B, Pärt T (2000) Influence of landscape scale on farmland birds breeding in semi-natural pastures. Conserv Biol 14:522-533

Spiecker H (2003) Silvicultural management in maintaining biodiversity and resistance of forests in Europe-temperate zone. J Environ Manag 67:55-65

Südbeck P, Andretzke H, Fischer S, Gedeon K, Schikore T, Schröder K, Sudfeldt C (eds) (2005) Methodenstandards zur Erfassung der Brutvögel Deutschlands, Radolfzell

Sudfeldt C, Dröschmeister R, Wahl J, Berlin K, Gottschalk T, Grünberg C, Mitschke A, Trautmann S (2012) Vogelmonitoring in Deutschland. Naturschutz und Biologische Vielfalt, Landwirtschaftsverlag Münster

Synes NW, Osborne PE (2011) Choice of predictor variables as a source of uncertainty in continental-scale species distribution modelling under climate change. Glob Ecol Biogeogr 20:904-914

Thomas L, Buckland ST, Rexstad E, Laake JL, Strindberg S, Hedley SL, Bishop JRB, Marques TA (2010) Distance software: design and analysis of distance sampling surveys for estimating population size. J Appl Ecol 47:5-14

Vermessungsverwaltungen der Bundesländer und BKG (2009) Digitales Geländemodell für Deutschland (DGM-D)

Virkkala R, Heikkinen RK, Leikola N, Luoto M (2008) Projected largescale range reductions of northern-boreal land bird species due to climate change. Biol Conserv 141:1343-1353 